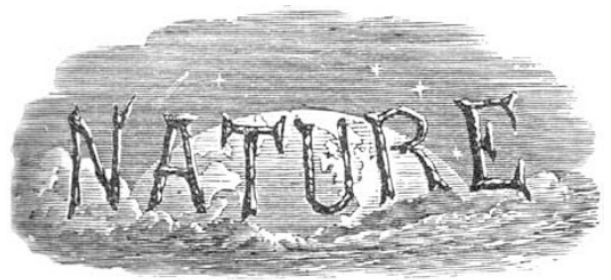

SATURDAY, NOVEMBER 27, I926.

\title{
Science and the Press.
}

UDGING from the Press reports of the Oxford $\int$ meeting of the British Association, it is obvious that there is a considerable variety of opinion among editors regarding the appreciation of science among their readers. Some pander to the kinema mind and attempt to make the news which they have obtained from a news agency attractive by giving it captious titles such as "Why Mosquitoes Prefer Blondes," "Are Bald Men Brainiest?" "Bobbing Eases the Mind," or seize upon a chance illustration regarding the frayed edge of a collar as a pretext for the assertion that science is rediscovering what every woman knows. Others evidently care for little except the sensational or ultra-controversial subjects, giving the greatest prominence to speculative fields of inquiry and ignoring the substantial advances which have been made in knowledge during the past few years.

It is most gratifying, however, that there are now many editors who have become aware of the increasing demand for accurate presentation of facts as stated by the masters of science, and tend to leave their readers to draw their own deductions from the facts presented. As might be expected, these editors show a nice sense of differentiation between the 'givers' and the 'takers': between those who take every advantage of the facilities afforded at the meeting of the Association to make a wider public acquainted with the recent advances in knowledge, and those who abuse their position by indulging in self-advertisement or putting forth theories which are based upon nothing more substantial than their prejudices and predilections.

Whatever the form in which it is presented, science is now considered good ' copy.' Moreover, it is good copy for all types of journals, from the great national newspapers down to the parish-pump periodical. It may distress some scientific workers that an enterprising reporter of an obscure suburban journal should canvas the local barbers on their views on "What Time hath scanted men in hair, he hath given them in wit," the Shakespearian quotation which Dr. Gunther considered apposite to his thesis on "The Hairlessness of Man." Some may feel that most sections of the Press attached exaggerated importance to the views of Sir Oliver Lodge on the imperishability of the individual spirit of man: others may deplore the reporter's partiality for the easily assimilated contributions to knowledge which are characteristic of such sections as agriculture, education, and geography, or that a broad survey of the recent applications of science to the solution of the pressing problems of industry, public health, and the nation's food supplies and defence, should prove more attractive to editors than

Telegraphic Address: PHUSIS, WESTRAND, LONDON. NO. 2978, VOL. I I 8$]$ 
a brilliant analysis of the phenomena of line spectra. Many of those who read papers before the sections of the British Association may feel aggrieved that the substance of their contributions is neglected, while considerable importance is attached to their incidental analogies. Then again, there is the large class of contributors whose papers are ignored altogether in the newspapers, and this is frequently attributed to the reporter's preference for the contributions of scientific workers of well-established reputation, or for those of distinguished laymen.

It is obvious there must be selection. A modest estimate of the average daily output during the Oxford meeting would be sixty papers. To do bare justice to them all, the newspapers would need to devote at least thirty columns daily to science news, and this would involve the employment of a staff of scientific experts for each newspaper, unless all editors were prepared to present to their readers exactly the same copy. But if the public demand for science news were sufficiently great to warrant such wholesale circulation, it is clear that it would also be sufficient to justify the publication of a science daily newspaper.

In existing circumstances, editors will select those items of news which they think will appeal to their particular public. But any author of a paper can help them materially in this process of selection if he will take the trouble to prepare for the official programme of the Association, a summary which is not only written in language intelligible to the average welleducated member of the community, but also calculated to awaken interest either from the newness of its facts or the novelty of their presentation. It is useful if, in addition, one or two copies of his complete paper are available in advance to the reporters in the Press Bureau, as this widens the scope of selection of individual reporters. Attention to such matters as these will usually safeguard an author against misrepresentation of his facts, theories, and opinions. The title given to a paper is also important in this connexion. "The Hygroscopic Relations of Colloidal Fibres" conveys all that is necessary to members of Section A, but is not likely to interest a reporter with limited space and time at his command, who sees, moreover, that there are a dozen other papers with far more attractive titles to be delivered the same day. $\mathrm{He}$ is only human in preferring to look to papers on "Intelligence in Rats," the "Psychology of Patriotism," or "The Public Schools and National Life" for his copy.

It is not suggested that scientific workers should aim at providing reporters with 'stunts,' or that the importance of scientific investigations be judged by their immediate value as copy for newspapers or topics of conversation. But it is clearly worth while to present the results of investigation in any one branch of science and theories based upon them, in a form which will enable every scientific worker, as well as the specialist, to appreciate them. Since the general public is also interested in science, there seems every reason why it should be provided with the best of science, and every assistance given to reporters-the channels of communication between science and the public-in the difficult task of selection and presentation. Serious scientific workers are themselves partly to blame for having the patient work of years dismissed in three or four unintelligible lines. They have put a new weapon in the hands of humanity; they have insensibly imposed upon it a new mental outlook; upon them devolves the responsibility of enabling all members of the community to understand the functions, aims, and methods of science, and the essence of the scientific spirit, its fearlessness in facing facts, its determination to resist prejudice, and its constant researches to test the validity of theories or the universality of laws.

If scientific workers will not seriously apply themselves to the task of securing greater and better publicity for their work, other than that which they obtain in the scientific and technical press, and reports of proceedings of learned societies and institutions, they must not complain of the manner of the publicity. They must be prepared for valuable utterances and suggestive discussions to be neglected in favour of the trivial and fantastic contributions made to the proceedings by our scientific entertainers - the terms in which the Saturday Review described the press reports of the Oxford meeting of the British Association. Yet there is now less justification for this criticism than formerly, since recently the Press, taken as a whole, has progressively improved its performance in separating the grain from the chaff. Many of the principal newspapers now have at their disposal the services of journalists who are also scientific writers of distinction. The daily reports of the Oxford meeting in the principal London and provincial journals were fuller than ever before, and considering the circumstances in which they were compiled, remarkably fair and accurate. Naturally, newspapers like the Times can devote more columns to the proceedings than those in the class typified by the Daily Express and the Daily Neres, but little exception could be taken to the reports as a whole. They flattered the intelligence of their readers. Moreover, many of these journals maintained a running fire of comment in leading articles on the more important. papers delivered, a striking commentary on the interest in science which the meeting provokes.

There is little doubt that this interest could be sustained. The Daily Express published recently a series of articles by eminent scientific workers. Most.

$$
\text { NO. 2978, VOL. II } 8 \text { ] }
$$


of the serious weekly periodicals devote some space to scientific subjects. The day cannot be far distant when the editors of the Observer and the Sunday Times will make a science page as regular a feature of their papers as their literature, music, and dramatic art pages. It is not improbable that the demand for scientific information is great. enough to justify the publication of a science daily newspaper, or at least a sound and popular science weekly, written in a form calculated to appeal to a wider public than Nature. There are daily and weekly journals devoted to finance, and these are not read solely by professional financiers.

The steps which might be taken by scientific workers to satisfy the public demand for knowledge of their work have already been the subject of comment in these columns. Reference has also been made to what has been done in the United States, by scientific workers themselves, to deal with a like situation. It is obvious that where there is a demand it will be satisfied by somebody. If the scientific community in Great Britain wishes to safeguard itself against the kind of misrepresentation of its endeavours which masquerades in the guise of 'popular science,' if it wishes to safeguard those members of the public interested in science progress against exploitation by enterprising advertisement agencies, there is no time to be lost. The opportunity to give the best of science to the nation exists. Do scientific workers possess the will and energy to take advantage of the present favourable situation?

\section{The Electricity Bill.}

$\mathrm{T}$ HE Electricity Bill, after passing its third reading in the House of Commons, is now being considered in the Upper House. As there were twentysix pages of amendments to be discussed and the bill is of a highly technical nature, the task was no easy one, but it started auspiciously. In the committee stage the bill was discussed from almost every point of view, and so it is unlikely that any serious flaw has been overlooked. Many politicians think that this bill makes a long step in the direction of nationalisation. In the opinion of the Government, however, it will stop nationalisation. It is pointed out that the electric supply industry is on a quite different footing from other industries. In every district of Great Britain electric supply is a monopoly. It is urged, therefore, that the industry should not be deprived of the great benefit that would ensue when cooperation and centralisation replace individual effort. The need for passing the bill at once is imperative, as several schemes for developing electrical supply are being held up pending the new legislation.

NO. 2978 , VOL. II 87
The amendment adopted by the Government making it obligatory instead of permissible for the Electricity Board to advance free of interest such sums as might be necessary to enable authorised undertakers or owners to alter their frequency, will probably meet the chief objection of many opponents of the bill.

It will be remembered that the origin of the bill was the desire expressed by many engineers to increase the interconnexion of networks of electricity supply in Great Britain. The primary object of the bill was to increase the efficiency of the supply. It will probably follow that an increase in the retail supply and a lowering in the price of electricity will take place concurrently. In Canada and the United States there are huge supply networks covering many thousands of square miles. The Pacific Gas and South Californian Edison Companies network covers 120,000 square miles and links up I 30 stations, which is more than double the area covered by the Government scheme.

The Electricity Commissioners have pointed out that $5^{6}$ per cent. of the capital of electricity undertakings is locked up in spare plant. If complete interconnexion were established, this could be reduced very considerably. This is one of the principal gains which the promoters of the bill hope to secure. In due time considerable savings will doubtless be effected, and care has been taken to ensure that the consumer will benefit largely by them.

In our opinion this scheme will be a boon to both the country and the industry, provided that no undue delay ensues before it is put into operation. A really forward policy need not involve large expenditure. The Electricity Commissioners' Reports prove conclusively that many of the electricity networks in Great Britain are inadequate and were very expensive to construct. In some cases the cost per unit of maximum demand is about twenty times as great as that of the most efficient stations. The multiplicity and variety of the systems of supply in London, although largely due to early electrical legislation which established two competing companies in each local area, is not creditable to electrical engineers. Figures have proved the great economies that could be effected without even the necessity of scrapping plant the efficiency of which is only fair. A first step in the direction of improvement has been the standardisation of the pressure of supply. Whenever new schemes have been sanctioned or systems changed from direct current to alternating current, or even in those cases where direct current is being retained, the pressure of supply is now 230 volts.

We are glad to see that progress is being made by electrical manufacturers in the direction of cheaper 